\title{
Effect of alkaline treatment on mechanical, physical and thermal properties of roselle/sugar palm fiber reinforced thermoplastic polyurethane hybrid composites
}

\begin{abstract}
The aim for this work is to investigate the effect of alkaline treatment on the mechanical, physical and thermal properties of roselle (RF)/sugar palm fiber (SPF) reinforced thermoplastic polyurethane hybrid composites. RF/SPF hybrid composites were fabricated at different $\mathrm{NaOH}$ concentrations $(3 \%, 6 \%$ and $9 \%)$ by melt mixing and compression molding. The mechanical, physical and thermal properties of RF/SPF hybrid composites were measured. The morphological properties of the tensile fractured sample were examined using scanning electron microscope. Obtained results indicated that the effect of $\mathrm{NaOH}$ treatment on the surface improved mechanical, physical and thermal properties accompanied by lower impact resistance. The highest tensile is $14.26 \mathrm{MPa}$, flexural strength is $14.05 \mathrm{MPa}$ and impact strength is 23.76 $\mathrm{kJ} / \mathrm{M} 2$ ) was obtained from treatment $6 \% \mathrm{NaOH}$ concentration on RF/SPF hybrid composites. Adhesion bonding between fiber and matrix was evident by using Scanning electron microscopy (SEM) micrograph of hybrid composite tensile fractured. Scanning electron micrograph of tensile fractured surfaces of the $\mathrm{NaOH}$ treated RF/SPF hybrid composites revealed good adhesion bonding between fiber and matrix. Fourier transform infrared spectroscopy analysis was used to observe the effectiveness of $\mathrm{NaOH}$ treatment in the removal impurities on fiber surfaces. Thermogravimetric analysis showed that the treated RF/SPF hybrid composites had improved the thermal stability. Physical properties showed lower water uptake of the treated thermoplastic polyurethane hybrid composites. The lowest water uptake is $7.97 \%$ and thickness swelling is $6.49 \%$ obtained from $9 \% \mathrm{NaOH}$ concentration after soaked in water for 7 days. Overall, the surface treatment on RF/SPF hybrid composite has enhanced the composite properties and suitable for automotive part application; battery holder and bottom based.
\end{abstract}

Keyword: Roselle fiber; Sugar palm fiber; Hybrid composites; Thermoplastic polyurethane; Alkaline treatment 
